\title{
Detailed modeling of carbon oxidation
}

\author{
Per-Anders Carlsson* \\ Department of Chemical and Biological Engineering and Competence Centre for Catalysis, \\ Chalmers University of Technology, SE-412 96 Göteborg, Sweden \\ E-mail: per-anders.carlsson@chalmers.se
}

\begin{abstract}
The kinetics of low-temperature oxidation of a synthetic carbon black material, i.e. Printex$\mathrm{U}$, by gaseous oxygen is modeled via conventional mean-field treatment of various detailed reaction schemes as well as lumped models. The significance of different elementary steps is elucidated by comparing predicted $\mathrm{CO}$ and $\mathrm{CO}_{2}$ formation during temperature programmed and isothermal carbon oxidation with the corresponding experimental data. In specific the connection between oxidation rate and surface coverages of reaction intermediates is demonstrated. The results suggest that activation of the carbon surface by oxygen adsorption is a key-step for further carbon oxidation and that gas phase oxygen plays a direct role in the formation of $\mathrm{CO}$ and $\mathrm{CO}_{2}$. Furthermore, the results suggest that Printex-U is preferably modeled as spherical shaped particles, especially at high conversion stages.
\end{abstract}

\section{Introduction}

The elementary reactions of oxidation of solid carbon materials are central in particulate emission control from combustion engines ${ }^{1-3}$ as well as in energy conversion of coal and biomass. ${ }^{4}$ In practice, the reactivity towards oxidation of a carbon material is complex, depending on material properties like the chemical composition with the chemical functional surface groups as of particular

\footnotetext{
*To whom correspondence should be addressed
} 
importance, ${ }^{5-8}$ and physical structure, e.g., size distribution, ${ }^{9}$ porosity ${ }^{10}$ and crystallinity. ${ }^{3}$ In addition, the reactivity of a certain carbon material usually changes with progressing oxidation. ${ }^{11-15}$ In order to, at least partly, overcome this complexity, fundamental studies are often carried out with more homogeneous carbon materials like Printex-U. ${ }^{15-17}$ Printex-U is an industrially produced carbon black material ${ }^{1}$ consisting of carbon particles with a diameter of about $25 \mathrm{~nm}$ and a BET surface area of about $100 \mathrm{~m}^{2} / \mathrm{g}$ and has been considered relevant for mimicking real diesel soot. ${ }^{15,16}$

In the open literature, the majority of the kinetic models of carbon oxidation are based on global kinetics usually expressed as;

$$
\text { rate }=N_{\text {tot }} k(T) f\left(p_{O_{2}}, p_{H_{2} O}, \ldots\right)
$$

where $N_{t o t}$ is the total number of active sites, $k(T)$ is the rate constant of Arrhenius type and $f\left(p_{O_{2}}, p_{\mathrm{H}_{2} \mathrm{O}}, \ldots\right)$ is a function which describes the dependence of the reaction rate on the partial pressures of various reactants. ${ }^{1,15,18}$ The global kinetic models, as mentioned here, and semi-global models ${ }^{19}$ are essentially designed for prediction of carbon consumption. Thus, these models can not be used to simulate carbon activation mechanisms or reaction selectivity, i.e, the prediction of formation of gaseous $\mathrm{CO}$ and $\mathrm{CO}_{2}$ during progressing carbon oxidation. To facilitate such simulations the model equations must rely on more detailed reaction schemes, preferably on a sequence of elementary steps. ${ }^{20}$ In this study the conventional mean-field treatment of various detailed reaction schemes is adopted to model the kinetics of low-temperature oxidation of Printex$\mathrm{U}$ by gaseous oxygen. This approach is analogous with that commonly used for modeling of heterogeneous catalytic reactions. ${ }^{20,21}$ Also, different lumped models are considered.

The objective with the present work is to explore mechanistic elementary reaction steps for low-temperature oxidation of solid carbon by comparisons with experimental data for oxidation of Printex-U. ${ }^{18,22}$ Further, the structures of the kinetic models required for description of $\mathrm{CO} / \mathrm{CO}_{2}$ selectivity and oxidation maxima as a function of progressing carbon oxidation and temperature

\footnotetext{
${ }^{1}$ www.degussa.com
} 
are discussed.

\section{Carbon-oxygen reactions}

Considering oxidation of carbon materials, it is clear that formations of various surface oxide complexes are crucial steps in the detailed reaction scheme. The oxide complexes then transform into gaseous $\mathrm{CO}$ and $\mathrm{CO}_{2}$ via endothermic processes and/or react further with oxygen supplied either from the gas phase or via the carbon surface. In the open literature, different steps and mechanisms for formation of surface oxide complexes, $\mathrm{CO}$ and $\mathrm{CO}_{2}$ has ben proposed and hereunder some the most important results are reviewed.

\section{Formation of surface oxide complexes}

On the basis of temperature programmed desorption (TPD) ${ }^{23-25}$ and gravimetric experiments 25 it has been concluded that formation of surface oxide complexes at low temperatures occurs via an initial step involving a molecular surface oxide complex here denoted $\mathrm{C}\left(\mathrm{O}_{2}\right)$. For continuous oxidation, i.e., temperature programmed oxidation (TPO), of carbon materials, Li et al. ${ }^{26}$ assumed an equilibrium between $\mathrm{C}\left(\mathrm{O}_{2}\right)$ and oxygen in gas phase according to

$$
\left(\mathrm{O}_{2}\right)_{\text {gas }}+\mathrm{C}_{f} \rightleftarrows \mathrm{C}\left(\mathrm{O}_{2}\right)
$$

where $\mathrm{C}_{f}$ is a free active site on the carbon surface. ${ }^{23-26}$ The $\mathrm{C}\left(\mathrm{O}_{2}\right)$, which also is referred to as stabilised molecular oxygen, ${ }^{27}$ is metastable and the rearrangement to the more stable atomic oxygen complex occurs. For this process Ahmed et al. ${ }^{23,24}$ proposed the following step where $\mathrm{C}\left(\mathrm{O}_{2}\right)$ slowly transforms into the more stable $\mathrm{C}(\mathrm{O})$,

$$
\mathrm{C}\left(\mathrm{O}_{2}\right)+\mathrm{C}_{f} \rightarrow 2 \mathrm{C}(\mathrm{O})
$$


Essenhigh ${ }^{28}$ proposed for the same rearrangement an equilibrium based on the combination of step (2) and (3),

$$
\left(\mathrm{O}_{2}\right)_{\text {gas }}+2 \mathrm{C}_{f} \rightleftarrows 2 \mathrm{C}(\mathrm{O})
$$

Using a different nomenclature Yang et al. considered the dissociation of oxygen to results in adsorbed atomic oxygen, denoted with $\mathrm{O}_{a d s}$, which then reacts further with carbon from the solid, denoted $\mathrm{C}(\mathrm{s})$, to form adsorbed $\mathrm{CO}^{29}$ according to the equilibrium reaction

$$
\mathrm{O}_{a d s}+\mathrm{C}(\mathrm{s}) \rightleftarrows \mathrm{CO}_{a d s} .
$$

Another approach was used by Lear at al. ${ }^{25}$ who considered the $\mathrm{C}\left(\mathrm{O}_{2}\right)$ complex to be stabilised by further reaction with gaseous oxygen forming not only atomic surface oxygen complexes but also, mainly, gaseous $\mathrm{CO}_{2}$, i.e.,

$$
\left(\mathrm{O}_{2}\right)_{\text {gas }}+\mathrm{C}\left(\mathrm{O}_{2}\right) \rightarrow \mathrm{C}(\mathrm{O})+\left(\mathrm{CO}_{2}\right)_{\text {gas }} \text {. }
$$

It may be appropriate to mention that step (6) is an unbalanced reaction. In the carbon literature such unbalanced reactions are not rare even though, for several reasons, balanced reactions are preferable. This is considered in more detail below. The steps (3)-(5) involving transformation of the metastable complex are all exothermic as more energetically favored structures are formed. ${ }^{25}$ In another scenario Tucker et al. ${ }^{30}$ suggested that oxygen molecules directly react with labile carbon atoms according to

$$
\left(\mathrm{O}_{2}\right)_{\text {gas }}+2 \mathrm{C}_{f} \rightarrow \mathrm{C}(\mathrm{O})+\mathrm{CO}_{\text {gas }} .
$$




\section{Formation of $\mathrm{CO}$ and $\mathrm{CO}_{2}$}

The formation of surface oxide complexes may to some extent involve production of $\mathrm{CO}$ and $\mathrm{CO}_{2}$, $c f$. step (6) and (7) described above. The main steps, however, for both $\mathrm{CO}$ and $\mathrm{CO}_{2}$ formation are usually considered as decomposition/desorption of surface oxides. Ahmed et al. ${ }^{23,24}$ considered desorption of atomic oxygen complexes as the main route for $\mathrm{CO}$ production

$$
\mathrm{C}(\mathrm{O}) \rightarrow \mathrm{CO}_{\text {gas }}+\mathrm{C}_{f}
$$

According to Lear et al. ${ }^{25}$ TPD experiments of oxygen-preexposed carbon samples support this step at high temperatures; however, at low temperatures, thermal decomposition of residual $\mathrm{C}\left(\mathrm{O}_{2}\right)$ complexes into $\mathrm{C}(\mathrm{O})$ and $\mathrm{CO}_{\text {gas }}$ as the main gaseous product occurs,

$$
\mathrm{C}\left(\mathrm{O}_{2}\right) \rightarrow \mathrm{C}(\mathrm{O})+\mathrm{CO}_{\text {gas }}
$$

Yang et al. ${ }^{29}$ expressed the formation of carbon monoxide by the $\mathrm{CO}$ adsorption-desorption equilibrium;

$$
\mathrm{CO}_{a d s} \rightleftarrows \mathrm{CO}_{\text {gas }}
$$

For $\mathrm{CO}_{2}$ formation it has been debated whether $\mathrm{CO}_{2}$ originates from surface oxide complexes as described here, in this case $\mathrm{CO}_{2}$ is referred to as a primary product, or from other oxygen containing species. In the latter case the formed $\mathrm{CO}_{2}$ is called a secondary product. For example Hayhurst et al. ${ }^{31}$ suggested that at high temperatures $\mathrm{CO}$ may react with species like $\mathrm{HO}_{2}$ and $\mathrm{OH}$ to form secondary $\mathrm{CO}_{2}$. Most authors, however, consider primary $\mathrm{CO}_{2}$ formation as the main route $^{23-27,32,33}$ even if the specific mechanisms for decomposition are not fully clear. Walker et $a l .{ }^{32}$ proposed the following reaction

$$
\mathrm{C}(2 \mathrm{O}) \rightarrow\left(\mathrm{CO}_{2}\right)_{\text {gas }}
$$


On the basis of isotope labeling studies Vastola et al. ${ }^{33}$ proposed the reaction between two atomic surface complexes according to

$$
2 \mathrm{C}(\mathrm{O}) \rightarrow\left(\mathrm{CO}_{2}\right)_{\text {gas }}+\mathrm{C}_{f}
$$

This step was suggested also by other authors. ${ }^{23,24,27}$ In order to account for $\mathrm{CO}_{2}$ production by other processes than pure desorption of oxygen complexes, Ahmed et al. ${ }^{23,24}$ complemented step (9) by adding reaction between gas phase oxygen and $\mathrm{C}(\mathrm{O})$,

$$
\left(\mathrm{O}_{2}\right)_{\text {gas }}+\mathrm{C}(\mathrm{O})+\mathrm{C}_{f} \rightarrow\left(\mathrm{CO}_{2}\right)_{\text {gas }}+\mathrm{C}(\mathrm{O})+2 \mathrm{C}_{f}
$$

and reaction between atomic and molecular surface oxides

$$
\mathrm{C}(\mathrm{O})+\mathrm{C}\left(\mathrm{O}_{2}\right) \rightarrow\left(\mathrm{CO}_{2}\right)_{g a s}+\mathrm{C}(\mathrm{O})+\mathrm{C}_{f}
$$

In a similar attempt to complement step (9) Li et al. ${ }^{26}$ report the two reactions

$$
\mathrm{C}(\mathrm{O})+\mathrm{CO} \rightarrow\left(\mathrm{CO}_{2}\right)_{\text {gas }}+\mathrm{C}_{f}
$$

and

$$
2 \mathrm{C}(\mathrm{O})+1 / 2 \mathrm{O}_{2} \rightarrow\left(\mathrm{CO}_{2}\right)_{g a s}+\mathrm{C}_{f}
$$

In a very simple step Du et al. ${ }^{34}$ proposed $\mathrm{CO}_{2}$ formation by direct reaction of gaseous oxygen with carbon;

$$
\left(\mathrm{O}_{2}\right)_{\text {gas }}+\mathrm{C}_{f} \rightarrow\left(\mathrm{CO}_{2}\right)_{\text {gas }}
$$

The steps reviewed above provide a simplistic view on carbon oxidation including the formation 
of surface complexes, $\mathrm{CO}, \mathrm{CO}_{2}$ and the role of the active site. The full picture of carbon oxidation is of course much more complex. As an example one may think of the distribution of the main decomposition products $\mathrm{CO}$ and $\mathrm{CO}_{2}$ during, for example, a TPD experiment indicating a variety of oxide complexes with different stability, i.e., different sites on the carbon surface form different oxide complexes with different activation energy for desorption. For example, detailed diffuse reflectance infrared Fourier transform (DRIFT) spectroscopy experiments ${ }^{8}$ suggest that CO may be produced from decomposition of quinone, ether, carbonyl and phenol structures while $\mathrm{CO}_{2}$ is produced primarily via the decomposition of lactone and carboxylic groups on the carbon surface. Anhydride groups are suggested to produce both $\mathrm{CO}$ and $\mathrm{CO}_{2}$. To account for this is however beyond the scope of the present paper.

\section{Description of experiments}

As a basis for analysis and validation of the different models formulated hereunder experimental data for the oxidation of Printex-U with oxygen described in detail by Wang-Hansen et al. ${ }^{18}$ is used for comparison. A short description of the experimental approach is given here. Wang-Hansen et $a l .{ }^{18}$ recently developed a methodology involving careful consideration of sample preparation, reactor design and experimental procedures for analysis of the kinetics of gas-solid reactions in a broad context. Specifically the global kinetics of oxidation of Printex-U was studied. By a wellcontrolled solvent-free technique, Printex-U was deposited onto cordierite monolith substrates such that the oxidation process of Printex-U could be studied in a continuous gas flow reactor in the absence of diffusion limitations, temperature gradients, and hot zones. Thus the experimental data is highly reliable and serves as a reliable reference in this work. Temperature-programmed oxidation (TPO) experiments and isothermal oxygen step-response (SR) experiments were performed. The oxidation experiments were conducted at various levels of oxygen using a total gas flow of $1500 \mathrm{~mL} / \mathrm{min}$ (NTP) corresponding to a space velocity of about $12000 \mathrm{~h}^{-1}$. For the TPO experiments the sample temperature was first increased rapidly from room temperature to $100{ }^{\circ} \mathrm{C}$ 
and then linearly increased at a rate of $5{ }^{\circ} \mathrm{C} / \mathrm{min}$ to $750{ }^{\circ} \mathrm{C}$. No sample pretreatment was used in order to avoid possible desorption of volatile species ${ }^{34,35}$ and restructuring and/or partial gasification of Printex-U. The oxygen SR experiments were conducted at three temperatures for various oxygen levels. The temperatures were chosen as to achieve detectable amounts of formed $\mathrm{CO}$ and $\mathrm{CO}_{2}$, while also maintaining differential operation. In contrast to the TPO experiments, the SR experiments were conducted with samples that had been pretreated for 10 min in $\mathrm{N}_{2}$ at $700{ }^{\circ} \mathrm{C}$ to obtain a consistent initial condition. The results from both the TPO and SR experiments with 2 vol.- $\% \mathrm{O}_{2}$ is used throughout this study.

\section{Mean-field kinetics of carbon oxidation}

Construction of detailed kinetic models requires detailed reaction schemes preferably consisting of chemical elementary steps. Thus, a nomenclature analogous to conventional mean-field treatment of heterogeneous catalytic reactions with solid catalysts is used for the description of an active site, here denoted $s$, and the rates of individual reaction steps. As an example, this means that a molecular oxide complex is denoted $\left(\mathrm{O}_{2}\right)_{a d s}$ instead of $\mathrm{C}\left(\mathrm{O}_{2}\right)$ as used by others (see above). The present nomenclature facilitates the description of adsorption-desorption and reaction rates in terms of vacant sites and surface coverages, and conservation of active sites in each step is more clear. The latter is of course an approximation, however, to justify this approach one may recall that one turnover of a reaction or reaction scheme is a microscopic event corresponding to an infinitesimal small change in macroscopic variables, i.e., $\mathrm{CO}$ and $\mathrm{CO}_{2}$ concentration and carbon mass. The connection between surface kinetics and carbon mass is described in detail in the Appendix. To facilitate the comparison with the experimental data, the kinetic models are implemented in a software package, designed for simulation of mass and heat transport and detailed reaction kinetics in monolith structures, and is described elsewhere. ${ }^{36}$ However, the use of rigorous mass and heat transport models are not crucial in the present work as the experiments to be mimicked were carried out in the absence of diffusion limitations, ${ }^{18}$ but is included rather for 
generality.

\section{Elementary step models}

One of the simplest sequences of elementary reaction steps describing the oxidation of solid carbon by oxygen into gaseous $\mathrm{CO}$ and $\mathrm{CO}_{2}$ is;

$$
\begin{array}{r}
\left(\mathrm{O}_{2}\right)_{g a s}+2 s \rightarrow 2 \mathrm{O}_{a d s} \\
\mathrm{O}_{a d s}+\mathrm{C} \rightarrow \mathrm{CO}_{a d s} \\
\mathrm{CO}_{a d s} \rightarrow \mathrm{CO}_{g a s}+s \\
2 \mathrm{CO}_{a d s} \rightarrow\left(\mathrm{CO}_{2}\right)_{g a s}+\mathrm{C}+2 s
\end{array}
$$

where the indices "gas" and "ads" denote gas phase and adsorbed species, respectively, C is a surface carbon atom and $s$ is an active site on the carbon surface. In this mechanism the sites are presumed to be of the same type. Furthermore oxygen is assumed to adsorb dissociatively occupying two active sites by formation of chemisorbed $\mathrm{O}$ atoms (step(18)), chemisorbed $\mathrm{O}$ may react with carbon from the solid to form adsorbed CO (step (19)) that may desorb (step (20)) or react further with another $\mathrm{CO}_{a d s}$ to form $\mathrm{CO}_{2}$, which immediately desorbs leaving one carbon to the solid and two free active sites (step (21)). The last step implies that formation of $\left(\mathrm{CO}_{2}\right)_{\text {gas }}$ can not be poisoned by CO. In this mechanism all steps are consecutive except steps (20) and (21), which may occur in parallel. Studies on oxygen surface diffusion show that diffusion of $\mathrm{O}_{a d s}$ species is appreciable on both graphitic ${ }^{37,38}$ and polycrystalline ${ }^{39}$ carbon surfaces. On the basis of mean-field theory one may thus to a good approximation express the reaction probabilities in terms of (average) surface coverages. The corresponding mean-field kinetic equations (Model 1) for steps (18)-(21) thus are;

$$
\begin{array}{r}
\frac{d \theta_{O}}{d t}=2 k_{18} p_{O_{2}} s_{O_{2}}^{0}\left(1-\theta_{O}-\theta_{C O}\right)^{2}-k_{19} \theta_{O} \\
\frac{d \theta_{C O}}{d t}=k_{19} \theta_{O}-k_{20} \theta_{C O}-2 k_{21} \theta_{C O}^{2}
\end{array}
$$


where $k_{18}-k_{21}$ are the rate constants of Arrhenius type, i.e., $k_{i}=v_{i} \exp \left[-E_{i} /(R T)\right]$ (here $v_{18} p_{O_{2}}$ is the impingement rate $(F)$ in line with collision theory of gases) for the reaction steps (18)-(21) and $\theta_{O}$ and $\theta_{C O}$ are the $\mathrm{O}$ and $\mathrm{CO}$ coverage, respectively. The oxygen partial pressure is denoted with $p_{\mathrm{O}_{2}}$ and $s_{\mathrm{O}_{2}}^{0}$ is the oxygen sticking coefficient on a bare carbon surface. The latter is included for the sake of completeness. As robust data on sticking probabilities is rare, $s_{O_{2}}^{0} \equiv 1$ is used throughout this study. The values for the kinetic parameters are summarised in Table 1. In Eq. (22) conventional mean-field treatment for dissociative adsorption of oxygen has been employed. Moreover, the last term presumes no need for vacant carbon sites to convert $\mathrm{O}_{a d s}$ into $\mathrm{CO}_{a d s}$ as here, adsorbed oxygen reacts directly with the carbon site. This formalism implies a simultaneous creation of a new site for the $\mathrm{CO}_{a d s}$ species.

Alternatively, $\mathrm{CO}_{2}$ production may occur via reaction between $\mathrm{CO}_{a d s}$ and $\mathrm{O}_{a d s}$ instead of via step (21), viz.;

$$
\mathrm{CO}_{a d s}+\mathrm{O}_{a d s} \rightarrow\left(\mathrm{CO}_{2}\right)_{g a s}+2 s
$$

The main difference compared to the previous reaction scheme is that here, the formation of gaseous $\mathrm{CO}_{2}$ may be limited by either $\mathrm{CO}$ or $\mathrm{O}$ coverage. In this case (Model 2) the last term in Eq. (23) is replaced with $k_{24} \theta_{C O} \theta_{O}$;

$$
\frac{d \theta_{C O}}{d t}=k_{19} \theta_{O}-k_{20} \theta_{C O}-k_{24} \theta_{C O} \theta_{O}
$$

In principle, these elementary four-step mechanisms contain all necessary characteristics to simulate the evolution of $\mathrm{CO}$ and $\mathrm{CO}_{2}$ during temperature programmed oxidation (TPO) of carbon materials.

In Figure 1 the results of calculations of TPO of Printex-U based on Eqs. (22) and (23) together with experimental data ${ }^{18}$ are shown. The corresponding results based on Eqs. (22) and (25) are displayed in Figure 2. As can be seen both models reproduce the experimental results with roughly the same accuracy. In both cases, the $\mathrm{O}$ coverage starts to build up below $450{ }^{\circ} \mathrm{C}$, reaches a 
maximum at around $560{ }^{\circ} \mathrm{C}$ and then declines during $\mathrm{CO}$ and $\mathrm{CO}_{2}$ production. The evolution of the $\mathrm{CO}$ coverage is somewhat different in the two cases due to the different mechanisms for $\mathrm{CO}_{2}$ production. One may notice that complete consumption of carbon occurs at around $700{ }^{\circ} \mathrm{C}$, carbon mass is zero, and thus the corresponding coverages has no physical meaning for this period. It is, based on the results presented in Figure 1 and Figure 2, not possible to judge weather $\mathrm{CO}_{2}$ may be produced from reaction between two adsorbed $\mathrm{CO}$ species or one $\mathrm{CO}$ and one $\mathrm{O}$ species. As mentioned above other reaction schemes, although not formulated as strictly as here, have also been used with similar qualitative results. For example, one may construct an even simpler model based on step (18) and the two following steps;

$$
\begin{gathered}
1 / 2\left(\mathrm{O}_{2}\right)_{\text {gas }}+\mathrm{C} \stackrel{O_{a d s}}{\longrightarrow} \mathrm{CO}_{\text {gas }} \\
\left(\mathrm{O}_{2}\right)_{\text {gas }}+\mathrm{C} \stackrel{O_{a d s}}{\longrightarrow}\left(\mathrm{CO}_{2}\right)_{\text {gas }}
\end{gathered}
$$

The steps (26) and (27) are analogous to step (13) proposed by Ahmed et al. ${ }^{23}$ As the steps (26)(27) in this scheme are not elementary, the physical interpretation of the reaction mechanism is not straightforward. For example step (26) includes both O+C reaction and $\mathrm{CO}$ desorption. Moreover both $\left(\mathrm{O}_{2}\right)_{g a s}$ and $\mathrm{O}_{a d s}$ are involved in the $\mathrm{O}+\mathrm{C}$ reaction. Here, it is not clear whether carbon reacts with oxygen already adsorbed on the carbon surface under the influence of gas phase oxygen or if the carbon reacts with gas phase oxygen under (catalytic) influence of adsorbed oxygen. The latter interpretation is assumed as indicated by the nomenclature. The corresponding reasoning for the formation of $\left(\mathrm{CO}_{2}\right)_{\text {gas }}$ is analogous. Considering product selectivity the main difference compared to the previous four-step models is that $\left(\mathrm{CO}_{2}\right)_{\text {gas }}$ is formed directly and not via formation of $\mathrm{CO}$. The mathematical description (Model 3) of this reaction scheme is based on a simplified expression for calculation of the oxygen surface coverage, i.e.;

$$
\frac{d \theta_{O}}{d t}=2 k_{18} p_{O_{2}} s_{O_{2}}^{0}\left(1-\theta_{O}\right)
$$


The reaction rates for $(\mathrm{CO})_{\text {gas }}$ and $\left(\mathrm{CO}_{2}\right)_{\text {gas }}$ formation are then given by;

$$
\begin{aligned}
r_{C O_{\text {gas }}} & =k_{26} p_{\mathrm{O}_{2}} \theta_{O} \\
r_{\left(\mathrm{CO}_{2}\right)_{\text {gas }}} & =k_{27} p_{\mathrm{O}_{2}} \theta_{O}
\end{aligned}
$$

Despite the low complexity and mathematical simplicity, which facilitate shorter simulation times, this model can be used with at least the same accuracy as the previous four-step models. Thanks to preservation of $\mathrm{O}_{a d s}$ during $(\mathrm{CO})_{\text {gas }}$ and $\left(\mathrm{CO}_{2}\right)_{\text {gas }}$ formation, i.e., oxygen coverage is increasing monotonically ( $c f$. Figure 3), the model parameters can be somewhat easier to tune although the model seems to be more sensitive to actual parameter values (see sensitivity analysis below).

From the results described so far one may conclude that a TPO experiment alone is insufficient for elucidating detailed reaction schemes as proposed by some authors. ${ }^{26}$ One reason for this is that in TPO experiments, temperature and carbon mass change simultaneously. To overcome this difficulty one can use either a series of TPO experiments with different temperature ramp speeds or oxygen step-response experiments at isothermal conditions as shown in, for example, Figure 4. Here, the latter approach is used where a stepwise increase in oxygen concentration is performed at $\mathrm{t}=1 \mathrm{~min}$ and the responses in $(\mathrm{CO})_{\text {gas }}$ and $\left(\mathrm{CO}_{2}\right)_{\text {gas }}$ outlet concentrations are measured. As can be clearly seen, the $(\mathrm{CO})_{\text {gas }}$ concentration passes through two maxima during the experiment. One sharp peak during approximately the first minute followed by another broader maximum. The initial peak reaches fairly the same level for the three temperatures, i.e., 580,605 and $630^{\circ} \mathrm{C}$, while the second maximum is clearly temperature dependent reaching higher levels as temperature is increased. The corresponding results for $\left(\mathrm{CO}_{2}\right)_{\text {gas }}$ is analogous. These results are discussed in more detail by Wang Hansen et al. ${ }^{18}$

At this point the underlying mechanisms are not clear, however, to facilitate the development of a plausible model structure a few different scenarios may be addressed. In scenario I the initial sharp peak is ascribed to highly reactive oxygen species, for example such species my originate from $\mathrm{OH}$ groups or adsorbed water, being rapidly consumed as oxygen is introduced. The second 
maximum is then due to a slow activation of the carbon surface by the build up of $\mathrm{O}$ coverage. The second scenario implies that the carbon material contains some minor amounts of highly reactive $\left(\right.$ labile $^{30}$ ) carbon species that is rapidly consumed as oxygen is introduced and, again, the second maximum is due to activation of the reminder of the carbon mass by a slow build up of $\mathrm{O}_{a d s}$ species. The latter scenario requires a model with two types of sites analogous with models previously proposed by Ahmed et al. ${ }^{23}$

\section{Models including reactive oxygen species (scenario I)}

The first model to address scenario I is based on the previous three-step model with the addition of two steps for formation $(\mathrm{CO})_{\text {gas }}$ and $\left(\mathrm{CO}_{2}\right)_{\text {gas }}$ from reactive oxygen species, here denoted $\mathrm{O}_{a d s}^{*}$, viz.;

$$
\begin{gathered}
1 / 2\left(\mathrm{O}_{2}\right)_{\text {gas }}+\mathrm{O}_{a d s}^{*}+\mathrm{C} \rightarrow \mathrm{CO}_{\text {gas }}+\mathrm{O}_{a d s} \\
1 / 2\left(\mathrm{O}_{2}\right)_{\text {gas }}+\mathrm{O}_{a d s}^{*}+\mathrm{C} \rightarrow\left(\mathrm{CO}_{2}\right)_{\text {gas }}+s
\end{gathered}
$$

The corresponding equations (Model 4) describing the $\mathrm{O}$ and $\mathrm{O}^{*}$ surface coverages and $(\mathrm{CO})_{\text {gas }}$ and $\left(\mathrm{CO}_{2}\right)_{\text {gas }}$ production are;

$$
\begin{array}{r}
\frac{d \theta_{O}}{d t}=2 k_{18} p_{O_{2}} s_{O_{2}}^{0}\left(1-\theta_{O}-\theta_{O^{*}}\right)^{2} \\
\frac{d \theta_{O^{*}}}{d t}=-k_{31} p_{O_{2}} \theta_{O^{*}}-k_{32} p_{O_{2}} \theta_{O^{*}} \\
r_{C O}=k_{26} p_{O_{2}} \theta_{O}+k_{31} p_{O_{2}} \theta_{O^{*}} \\
r_{C O_{2}}=k_{27} p_{O_{2}} \theta_{O}+k_{32} p_{O_{2}} \theta_{O^{*}}
\end{array}
$$

As the equations are analogous to the previous case no further interpretation is performed here. One may mention, however, that an assumption on the initial coverage of $\mathrm{O}^{*}$ species is necessary to reproduce the initial sharp peak. It turned out that with increasing temperature a lower initial coverage is needed to achieve reasonable results. Given that the original carbon samples are similar 
this trend is intuitively reasonable as reactive species to a larger extent may decompose at the higher temperatures.

In Figure 4 the results from this model together with experimental data are displayed. The general behavior with one sharp peak followed by a broader maximum in both $(\mathrm{CO})_{\text {gas }}$ and $\left(\mathrm{CO}_{2}\right)_{\text {gas }}$ is relatively well reproduced at all three temperatures. It is clear that the sharp peak origins from the more reactive oxygen species, the coverage of $\mathrm{O}^{*}$ species immediately starts to decrease when oxygen is introduced a $\mathrm{t}=1 \mathrm{~min}$. The broader maximum is then composed by the the build up of $\mathrm{O}_{a d s}$ as active sites become accessible via step (32), increasing $(\mathrm{CO})_{\text {gas }}$ and $\left(\mathrm{CO}_{2}\right)_{\text {gas }}$ formation, and carbon consumption during progressing oxidation, decreasing $(\mathrm{CO})_{\text {gas }}$ and $\left(\mathrm{CO}_{2}\right)_{\text {gas }}$ formation. Even though this lumped model gives reasonable results, it is interesting to study elementary reaction schemes including $\mathrm{O}_{a d s}$ and $\mathrm{O}_{a d s}^{*}$ species. It turns out that neither the reaction steps (18)(21) nor (18)-(19)+(21), both in combination with steps (26) and (27), can reproduce the isothermal experiments satisfactorily. For example the production of $\left(\mathrm{CO}_{2}\right)_{\text {gas }}$ is much lower than observed experimentally due to, in the former case, a too low $\mathrm{CO}$ coverage and, in the latter case, a too low oxygen coverage. As an increase of the respective rate for formation of $\mathrm{CO}_{a d s}$ and $\mathrm{O}_{a d s}$ in the two cases would lead to dynamic mismatch (a too narrow second peak) the situation can only bee achieved by increasing the number of sites, i.e. reduce the initial diameter of the carbon particles. However, to approach the experimental observations a decrease of the particle diameter of the order of one to two orders of magnitude is necessary, which is not realistic. For this reason an alternative lumped reaction scheme is adopted. Here, steps (18), (19), (31) and (32) are used together with the following two steps;

$$
\begin{gathered}
1 / 2\left(\mathrm{O}_{2}\right)_{\text {gas }}+\mathrm{CO}_{a d s} \rightarrow \mathrm{CO}_{\text {gas }}+\mathrm{O}_{a d s} \\
\left(\mathrm{O}_{2}\right)_{\text {gas }}+\mathrm{CO}_{a d s} \rightarrow\left(\mathrm{CO}_{2}\right)_{g a s}+\mathrm{O}_{a d s}
\end{gathered}
$$

In this reaction scheme gas phase oxygen is addressed to react with $\mathrm{CO}_{a d s}$ to form $(\mathrm{CO})_{\text {gas }}$ (step (37)) and/or $\left(\mathrm{CO}_{2}\right)_{\text {gas }}$ (step (38)) in both cases preserving $\mathrm{O}_{a d s}$. The corresponding equations 
(Model 5) used to describe this reaction scheme are;

$$
\begin{array}{r}
\frac{d \theta_{O}}{d t}=2 k_{18} p_{O_{2}} s_{O_{2}}^{0}\left(1-\theta_{O}-\theta_{O^{*}}-\theta_{C O}\right)^{2}- \\
k_{19} \theta_{O}+k_{31} p_{O_{2}} \theta_{C O}-k_{32} p_{O_{2}} \theta_{C O} \\
\frac{d \theta_{C O}}{d t}=k_{19} \theta_{O}-k_{31} p_{O_{2}} \theta_{C O}-k_{32} p_{O_{2}} \theta_{C O} \\
\frac{d \theta_{O^{*}}}{d t}=-k_{31} p_{O_{2}} \theta_{O}^{*}-k_{32} p_{O_{2}} \theta_{O^{*}}
\end{array}
$$

With suitable parameter values the $\mathrm{O}$ and $\mathrm{CO}$ coverages are appreciable facilitating sufficient $(\mathrm{CO})_{g a s}$ and $\left(\mathrm{CO}_{2}\right)_{\text {gas }}$ formation with reasonable dynamics, $c f$. Figure 5. As can be seen the general behavior is well reproduced and both the sharp and broad maximum are in good agreement with the experimental results. However, as the two models both predict reasonable formation

of $(\mathrm{CO})_{\text {gas }}$ and $\left(\mathrm{CO}_{2}\right)_{\text {gas }}$ a clear distinction is difficult without further experimental support. Thus it would be interesting to try to spectroscopically distinguish between $\mathrm{O}_{a d s}$ and $\mathrm{CO}_{a d s}$ to scrutinize the mechanisms.

\section{A model including reactive carbon species (scenario II)}

To mimic scenario II a model based on presuming two types of sites to mimic the presence of two types of carbons with different reactivity, i.e., the type of carbon that has been treated so far and a small proportion of highly reactive carbons, is employed. This model is constructed simply by using steps (18), (26) and (27) for the more abundant carbon (C) and an analogous sequence of steps for the highly reactive carbon here denoted with $\mathrm{C}^{*}$, i.e.;

$$
\begin{array}{r}
\left(\mathrm{O}_{2}\right)_{\text {gas }}+2 s^{*} \rightarrow 2 \mathrm{O}_{a d s, s^{*}} \\
1 / 2\left(\mathrm{O}_{2}\right)_{\text {gas }}+\mathrm{C}^{*} \stackrel{O_{a d s, s^{*}}}{\longrightarrow} \mathrm{CO}_{\text {gas }} \\
\left(\mathrm{O}_{2}\right)_{\text {gas }}+\mathrm{C}^{*} \stackrel{O_{a d s, s^{*}}}{\longrightarrow}\left(\mathrm{CO}_{2}\right)_{\text {gas }}
\end{array}
$$


where $s^{*}$ denotes the sites on the more reactive carbon. The corresponding kinetic equations (Model 6) are;

$$
\begin{gathered}
\frac{d \theta_{O}}{d t}=2 k_{18} p_{O_{2}} s_{O_{2}}^{0}\left(1-\theta_{O}\right) \\
\frac{d \theta_{O, s^{*}}}{d t}=2 k_{42} p_{O_{2}} s_{O_{2}}^{0}\left(1-\theta_{O, s^{*}}\right) \\
r_{C O}=k_{26} p_{O_{2}} \theta_{O}+k_{43} p_{O_{2}} \theta_{O, s^{*}} \\
r_{C O_{2}}=k_{27} p_{O_{2}} \theta_{O}+k_{44} p_{O_{2}} \theta_{O, s^{*}}
\end{gathered}
$$

The results shown in Figure 6 are similar to the results from the first model with reactive oxygen species, i.e, steps (33)-(36). The main difference is that here, the $(\mathrm{CO})_{\text {gas }}$ production is the sum of the respective non-competitive reactions occurring on the two types of carbons. The case of $\left(\mathrm{CO}_{2}\right)_{g a s}$ formation is analogous. In the former cases $\mathrm{O}_{a d s}$ and $\mathrm{O}_{a d s}^{*}$ compete for the same type of sites and thus the net $(\mathrm{CO})_{\text {gas }}$ and $\left(\mathrm{CO}_{2}\right)_{\text {gas }}$ formation is not a simple superposition of carbon consuming reactions but rather related to changes in the respective surface coverage.

\section{Parameter analysis}

Hitherto, the results have been discussed mainly in terms of reaction steps/schemes forming the structural basis of the models. As discussed above, to obtain a good fit, the structures of the models are here at least as important as the actual values of the kinetic parameters. Although a full statistical parameter analysis is beyond the present scope, it is appropriate to briefly comment on the employed activation energies. Also it is appropriate to pay some attention the sensitivity of the derived models and the assumptions of the initial shape, size and size distribution of the carbon spherules. 


\section{Activation energies and their influence on the $(\mathrm{CO})_{\text {gas }}$ formation}

Based on a global kinetic model where the $(\mathrm{CO})_{\text {gas }}$ and $\left(\mathrm{CO}_{2}\right)_{\text {gas }}$ formations were considered as separate reactions Wang-Hansen et al. ${ }^{18}$ found that the activation energy for the formation of $(\mathrm{CO})_{\text {gas }}$ and $\left(\mathrm{CO}_{2}\right)_{\text {gas }}$ at low conversions is about 155 and $110 \mathrm{~kJ} / \mathrm{mol}$, respectively. During progressing oxidation the activation energy for $(\mathrm{CO})_{\text {gas }}$ formation decrease to about $130 \mathrm{~kJ} / \mathrm{mol}$ while the activation energy for $\left(\mathrm{CO}_{2}\right)_{\text {gas }}$ formation is fairly constant. In the present work the corresponding activation energies are generally somewhat higher. For example for Model 3 the activation energy for $(\mathrm{CO})_{\text {gas }}$ and $\left(\mathrm{CO}_{2}\right)_{\text {gas }}$ formations is 178 and $144 \mathrm{~kJ} / \mathrm{mol}$, respectively, which correspond well with previous observations by Neeft et al., ${ }^{15}$ for a review see Refs. 2 and 3 and references therein. The values obtained for Models 4-6 is similar, see Table 1 . The trend with higher activation energy for formation of $(\mathrm{CO})_{\text {gas }}$ than for $\left(\mathrm{CO}_{2}\right)_{\text {gas }}$ corresponds well with previous results. ${ }^{18}$ Also, the activation energy for desorption of $\mathrm{CO}$ is higher than for oxygen adsorption in correspondence with previous data. ${ }^{19}$ It should be mentioned that a variation in the activation energies for the detailed models as compared to global models is expected as the estimation of the

activation energies are dependent on the assumed mechanisms. Also, in the global model, ${ }^{18}$ the kinetic parameters are conversion dependent. Another important aspect is the assumption on the initial shape, size and size distribution of the carbon spherules as this significantly influences the overall carbon oxidation and thus also the obtained kinetic parameters in a fitting procedure (see below).

To roughly analyse the sensitivity of the derived models the temperature shift for the peak production of $(\mathrm{CO})_{g a s}$ during TPO as a function of a change in various parameters is investigated. This is performed for Models 1-3. It is clear that Models 1 and 2 show similar sensitivity towards the changes in parameter values except for the case where the activation energy for the $(\mathrm{CO})_{\text {gas }}$ formation is changed, for which Model 2 is less sensitive. Moreover, Model 3 that relies on fewest chemical steps, is generally more sensitive. Model 1 and 2 are most sensitive to a change in the activation energy for formation of adsorbed $\mathrm{CO}$, while Model 3 is more sensitive to the corresponding change in activation energy for the formation gaseous $\mathrm{CO}$. This is of course due to that 
in Model 3, the formation of adsorbed and gaseous CO are lumped into the same step.

\section{Influence of carbon spherule shape and size on overall oxidation kinetics}

It has been shown that the shape and size distribution of carbon spherules may influence the overall kinetics of carbon oxidation appreciably. ${ }^{9}$ Therefore, a comment based on Model 3 and the assumption that carbon spherules oxidise from the periphery to the center, is made here. Figure 7 shows the evolution of $(\mathrm{CO})_{\text {gas }}$ predicted for carbon samples with different initial diameter $(5,15$, 25, 50 and $100 \mathrm{~nm}$ ) of either mono-sized spherical (top panel) or disc-like (bottom panel) carbon spherules. It is clear that the maximum $(\mathrm{CO})_{\text {gas }}$ formation rate is significantly shifted towards higher temperatures for both spherical and disc-like spherules as the spherule size is increased and that for disc-like spherules, the $(\mathrm{CO})_{\text {gas }}$ concentration drops more quickly after maximum $(\mathrm{CO})_{\text {gas }}$ formation. The former is due to the decreased number of sites (per mass carbon) with increasing diameter leading to a corresponding decrease in reaction rate. Here, however, this is not crucial as a possible error in initial diameter only systematically would influence the values of the frequency factors as the models are fitted against the same experimental data and the initial diameter has been fixed to the same value in all simulations. However, one should keep in mind that activation energies may be correlated with frequency factors and thus assumptions on size and shape may influence the obtained activation energies to some extent. Considering the shape of the spherules, the results of the TPO indicate that Printex-U is preferably modeled as spherical particles. The drop in $(\mathrm{CO})_{\text {gas }}$ concentration after the maximum is in better agreement with experimental observations. The results (not shown) for isothermal oxidation are analogous, i.e, the decay in (CO)gas and $\left(\mathrm{CO}_{2}\right)_{\text {gas }}$ concentrations after the second maximum is in better agreement with experiments

using spherical shaped spherules. This is in line with previous experimental results showing that the global reaction order approaches 0.7 at high conversions. ${ }^{18}$ 


\section{Concluding remarks}

Conventional mean-field treatment of reaction kinetics can be used to explore different mechanistic elementary reaction steps involved in oxidation of solid carbon by oxygen. By addressing various reaction schemes and corresponding kinetic equations, in some cases with lumped steps, the evolutions of $(\mathrm{CO})_{\text {gas }}$ and $\left(\mathrm{CO}_{2}\right)_{\text {gas }}$ during temperature programmed and isothermal oxidation of Printex-U have been simulated. By comparing the results with the corresponding experimental data, the significance of different key-steps and model structures have been elucidated. In specific, the connection between oxidation rate and surface coverages of reaction intermediates has been demonstrated. The results suggest that activation of carbon surface by oxygen adsorption is a crucial step for further carbon oxidation and that gas phase oxygen plays a direct role in the $(\mathrm{CO})_{\text {gas }}$ and $\left(\mathrm{CO}_{2}\right)_{\text {gas }}$ production. Further Printex-U is preferably modeled as spherical particles, especially at high conversion stages. However, it is clear that the present elementary step models can not explain the isothermal oxidation experiments completely. Additional characterization experiments, including in situ spectroscopy and microscopy methods, would likely be valuable as to distinguish between different surface oxide complexes, i.e., $\mathrm{O}_{a d s}$ and $\mathrm{CO}_{a d s}$, and thereby discriminate different kinetic models as well as explore other surface species involved in the carbon oxidation process.

\section{Acknowledgement}

This work has been supported by EMFO and the Competence Centre for Catalysis, which is hosted by Chalmers University of Technology and financially supported by the Swedish Energy Agency and the member companies AB Volvo, Volvo Car Corporation, Scania CV AB, GM Powertrain Sweden AB, Haldor Topsøe A/S, and The Swedish Space Agency. Prof. Bengt Andersson and Prof. Magnus Skoglundh are acknowledged for supportive discussions.

\section{Appendix}


To calculate the number of active sites $\left(n_{s}\right)$ the following procedure is adopted. First the the number of carbon spherules $\left(n_{c s}\right)$ is estimated assuming spherical shape with a diameter of $25 \mathrm{~nm}$. Based on this, the spherule diameter $(d)$ during progressing oxidation is calculated from the actual carbon mass $(m)$ via $d=\left[6 m /\left(n_{c s} \rho \pi\right]^{1 / 3}\right.$ where $\rho$ is the spherule density. The $n_{s}$ is then calculated by $\pi d^{2} n_{c s} /\left(a N_{A}\right)$, where $a$ is the area of an active site (here $8 \AA^{2}$ is used ${ }^{12}$ ) and $N_{A}$ is the Avogadro number.

The coupling between the microkinetics and carbon mass is then described by the differential equation;

$$
\frac{1}{M} \frac{d m}{d t}=-\sum r_{i}
$$

where $M$ is the carbon molar mass and $r_{i}$ is the reaction rate for reaction $i$.

\section{References}

(1) van Setten, B. A. A. L.; Makkee, M.; Moulijn, J. A. Catal. Rev. 2001, 43, 489-564.

(2) Messerer, A.; Niessner, R.; Pöschl, U. Carbon 2006, 44, 307-24.

(3) Stanmore, B. R.; Brilhac, J. F.; P.Gilot, Carbon 2001, 39, 2247-68.

(4) Bridgewater, A. V. Appl. Catal. A: General 1994, 116, 5-47.

(5) Mul, G.; Neeft, J. P. A.; Kapteijn, F.; Moulijn, J. A. Carbon 1998, 36, 1269-76.

(6) Muckenhuber, H.; Grothe, H. Carbon 2007, 45, 321-29.

(7) Muckenhuber, H.; Grothe, H. Carbon 2006, 44, 546.

(8) Setiabudi, A.; Makkee, M.; Moulijn, J. A. Appl. Catal. B Environ. 2004, 50, 185-94.

(9) Zhdanov, V. P.; Carlsson, P.-A.; Kasemo, B. Chem. Phys. Lett 2008, 454, 341-44. 
(10) Higgins, K. J.; Jung, H.; Kittelson, D. B.; Roberts, J. T.; Zachariah, M. R. J. Phys. Chem. A 2002, 106, 96-103.

(11) Smith, W. R.; Polley, M. H. J. Phys. Chem. 1956, 60, 689-91.

(12) Laine, N. R.; Vastola, F. J.; Walker, P. L. J. Phys. Chem. 1963, 67, 2030-34.

(13) Lizzio, A. A.; Jiang, H.; Radovic, L. R. Carbon 1990, 28, 7-19.

(14) Hoffman, W. P. Carbon 1991, 29, 769-76.

(15) Neeft, J. P. A.; Nijhuis, T. X.; Smakman, E.; Makkee, M.; Moulijn, J. A. Fuel 1997, 76, 1129-36.

(16) Nejar, N.; Makkee, M.; Illán-Gómez, M. J. Appl. Catal. B Environ. 2007, 75, 11-16.

(17) Yezeretz, A.; Currier, N. W.; Kim, D. H.; Eadler, H. A.; Epling, W. S.; Peden, C. H. F. Appl. Catal. B Environ. 2005, 61, 120-9.

(18) Wang-Hansen, C.; Kamp, C. J.; Skoglundh, M.; Andersson, B.; Carlsson, P.-A. J. Phys. Chem. C. 2011, 115, 16098-16108301.

(19) Hurt, R. H.; Calo, J. M. Comb. Flame 2001, 125, 1138-49.

(20) Stolze, P. Prog. Surf. Sci. 2000, 65, 65-150.

(21) Carlsson, P.-A.; Zhdanov, V. P.; Kasemo, B. Appl. Surf. Sci. 2005, 239, 424-31.

(22) Ericsson, P.; Holmström, M.; Amberntsson-Carlsson, A.; Ohlson, C.; Skoglundh, M.; Andersson, B.; Carlsson, P.-A. SAE technical paper series 2008, 2008-01-1746, .

(23) Ahmed, S.; Back, M. H. Carbon 1985, 23, 513-24.

(24) Ahmed, S.; Back, M. H.; Roscoe, J. M. Comb. Flame 1987, 70, 1-16.

(25) Lear, A. E.; Brown, T. C.; Haynes, B. S. Twenty-Third Symposium (International) on Combustion, 1991; pp 1191-8. 
(26) Li, C.; Brown, T. C. Carbon 2001, 39, 725-32.

(27) Marsh, H.; Foord, A. D. Carbon 1973, 11, 421-24.

(28) Essenhigh, R. H. Chemistry of Coal utilization; Wiley: New York, 1981; pp 1153-310.

(29) Yang, R. T.; Wong, C. J. Phys. Chem. 1980, 84, 678-79.

(30) Tucker, B. G.; Mulcachy, M. F. R. Trans. Farad. Soc. 1969, 65, 274-86.

(31) Hayhurst, A. N.; Parmar, M. S. Chem. Eng. Sci. 1998, 53, 427-38.

(32) Walker, P. L.; Taylor, R. L.; Ranish, J. M. Carbon 1991, 29, 411-21.

(33) Vastola, F. J.; Hart, P. J.; Walker, P. L. Carbon 1964, 2, 65-71.

(34) Du, Z.; Sarofirm, A. F.; Longwell, J. P.; C.Mims, Energy and Fuels 1991, 5, 214-21.

(35) Ciambelli, P.; D’Amore, M.; Palma, V.; Vaccaro, S. Catal. Today 1994, 99, 413.

(36) Carlsson, P.-A.; Skoglundh, M.; Thormählen, P.; Andersson, B. Top. Catal. 2004, 30/31, $375-81$.

(37) Walker, P. L.; Vastola, F. J.; Ranish, J. M. Fundamentals of gas-surface interactions; Academic Press: New York, 1967; p 307.

(38) Feates, F. S.; Robinsson, P. S. TITLE. Third conference on industrial carbons and graphite, 1971.

(39) Foord, A. D. Ph.D. thesis, University of Newcastle upon Tyne, 1972.

\section{Tables}


Table 1: Overview of the investigated models and the corresponding Arrhenius parameters, i.e., frequency factors and activation energies, for the rate constants of the individual elementary steps. The frequency factor for oxygen dissociation is defined as the impingement rate in line with collision theory of gases and is denoted $F$.

Step Frequency factor $(v)$ Activation energy, $E_{a}(\mathrm{~kJ} / \mathrm{mol})$

Model 1
$\left(\mathrm{O}_{2}\right)_{\text {gas }}+2 s \rightarrow 2 \mathrm{O}_{a d s}$
$\mathrm{O}_{a d s}+\mathrm{C} \rightarrow \mathrm{CO}_{a d s}$
$\mathrm{CO}_{a d s} \rightarrow \mathrm{CO}_{\text {gas }}+s$
$2 \mathrm{CO}_{a d s} \rightarrow\left(\mathrm{CO}_{2}\right)_{\text {gas }}+\mathrm{C}+2 s$

\section{Model 3}

$$
\begin{aligned}
& \left(\mathrm{O}_{2}\right)_{\text {gas }}+2 s \rightarrow 2 \mathrm{O}_{a d s} \\
& 1 / 2\left(\mathrm{O}_{2}\right)_{\text {gas }}+\mathrm{C} \stackrel{O_{a d s}}{\longrightarrow} \mathrm{CO}_{\text {gas }} \\
& \left(\mathrm{O}_{2}\right)_{\text {gas }}+\mathrm{C} \stackrel{O_{a d s}}{\longrightarrow}\left(\mathrm{CO}_{2}\right)_{\text {gas }}
\end{aligned}
$$

Model 4

$$
\begin{aligned}
& \left(\mathrm{O}_{2}\right)_{\text {gas }}+2 s \rightarrow 2 \mathrm{O}_{\text {ads }} \\
& 1 / 2\left(\mathrm{O}_{2}\right)_{\text {gas }}+\mathrm{C} \stackrel{O_{a d s}}{\longrightarrow} \mathrm{CO}_{\text {gas }} \\
& \left(\mathrm{O}_{2}\right)_{\text {gas }}+\mathrm{C} \stackrel{O_{a d s}}{\longrightarrow}\left(\mathrm{CO}_{2}\right)_{\text {gas }} \\
& 1 / 2\left(\mathrm{O}_{2}\right)_{\text {gas }}+\mathrm{O}_{a d s}^{*}+\mathrm{C} \rightarrow \mathrm{CO}_{\text {gas }}+\mathrm{O}_{\text {ads }} \\
& 1 / 2\left(\mathrm{O}_{2}\right)_{\text {gas }}+\mathrm{O}_{a d s}^{*}+\mathrm{C} \rightarrow\left(\mathrm{CO}_{2}\right)_{\text {gas }}+s
\end{aligned}
$$

Model 5

$\left(\mathrm{O}_{2}\right)_{\text {gas }}+2 s \rightarrow 2 \mathrm{O}_{\text {ads }}$

$\mathrm{O}_{a d s}+\mathrm{C} \rightarrow \mathrm{CO}_{a d s}$

$1 / 2\left(\mathrm{O}_{2}\right)_{\text {gas }}+\mathrm{O}_{a d s}^{*}+\mathrm{C} \rightarrow \mathrm{CO}_{\text {gas }}+\mathrm{O}_{a d s}$

$1 / 2\left(\mathrm{O}_{2}\right)_{\text {gas }}+\mathrm{O}_{a d s}^{*}+\mathrm{C} \rightarrow\left(\mathrm{CO}_{2}\right)_{\text {gas }}+s$

$1 / 2\left(\mathrm{O}_{2}\right)_{\text {gas }}+\mathrm{CO}_{a d s} \rightarrow \mathrm{CO}_{\text {gas }}+\mathrm{O}_{a d s}$

$\left(\mathrm{O}_{2}\right)_{g a s}+\mathrm{CO}_{a d s} \rightarrow\left(\mathrm{CO}_{2}\right)_{g a s}+\mathrm{O}_{a d s}$

Model 6

$$
\begin{aligned}
& \left(\mathrm{O}_{2}\right)_{\text {gas }}+2 s \rightarrow 2 \mathrm{O}_{a d s} \\
& 1 / 2\left(\mathrm{O}_{2}\right)_{\text {gas }}+\mathrm{C} \stackrel{O_{a d s}}{\longrightarrow} \mathrm{CO}_{\text {gas }} \\
& \left(\mathrm{O}_{2}\right)_{\text {gas }}+\mathrm{C} \stackrel{O_{a d s}}{\longrightarrow}\left(\mathrm{CO}_{2}\right)_{\text {gas }} \\
& \left(\mathrm{O}_{2}\right)_{\text {gas }}+2 s^{*} \rightarrow 2 \mathrm{O}_{a d s, s^{*}} \\
& 1 / 2\left(\mathrm{O}_{2}\right)_{\text {gas }}+\mathrm{C}^{*} \stackrel{O_{a d s, s^{*}}}{\longrightarrow} \mathrm{CO}_{\text {gas }} \\
& \left(\mathrm{O}_{2}\right)_{\text {gas }}+\mathrm{C}^{*} \stackrel{O_{a d s, s^{*}}}{\longrightarrow}\left(\mathrm{CO}_{2}\right)_{\text {gas }}
\end{aligned}
$$

$F$

$5 \mathrm{e} 9$

$8 \mathrm{e} 12$

3e15

142

197

197

182

$\begin{array}{cc}F & 142 \\ 5 \mathrm{e} 9 & 200 \\ 1.5 \mathrm{e} 11 & 198 \\ 4 \mathrm{e} 10 & 188\end{array}$

F

157

$6 \mathrm{e} 4$

178

$3 \mathrm{e} 2$

144

F

157

$6 e 4$

178

$3 \mathrm{e} 2$

144

$5 \mathrm{e} 4$

170

$5 \mathrm{e} 2$

140

$\begin{array}{cc}F & 158 \\ 3 \mathrm{e} 9 & 185 \\ 4 \mathrm{e} 4 & 178 \\ 2 \mathrm{e} 2 & 144 \\ 5 \mathrm{e} 4 & 170 \\ 5 \mathrm{e} 2 & 140\end{array}$

F

157

$6 \mathrm{e} 4$

178

$3 \mathrm{e} 2$

144

F

120

$1 \mathrm{e} 5$

170

1e3

140 
Table 2: Summary of sensitivity analysis of various parameters for the three models used to mimic the temperature programmed oxidation experiments described in Ref. 18.

\begin{tabular}{lccccc}
\hline Elementary step & Parameter & Change & \multicolumn{3}{c}{ Shift of $(\mathrm{CO})_{\text {gas }}$ peak position $\left({ }^{\circ} \mathrm{C}\right)$} \\
\hline \multirow{2}{*}{ Oxygen dissociation } & $p_{O_{2}}$ & $+20 \%$ & -2 & -2 & -6 \\
$"$ & $"$ & $+5 \%$ & -2 & 0 & -2 \\
$"$ & $"$ & $-5 \%$ & 0 & 0 & 2 \\
$"$ & $"$ & $-20 \%$ & 2 & 5 & 10 \\
$"$ & $\mathrm{E}_{18}$ & $+5 \%$ & 14 & 14 & 14 \\
$"$ & $"$ & $-5 \%$ & -10 & -10 & -4 \\
$(\mathrm{CO})_{\text {ads }}$ formation & $\mathrm{E}_{19}$ & $+5 \%$ & 30 & 34 & - \\
$"$ & $"$ & $-5 \%$ & -24 & -30 & - \\
$(\mathrm{CO})_{\text {gas }}$ formation & $\mathrm{E}_{20}$ & $+5 \%$ & 12 & 6 & - \\
$"$ & $"$ & $-5 \%$ & -10 & -4 & - \\
$"$ & $\mathrm{E}_{26}$ & $+5 \%$ & - & - & -24 \\
$(\mathrm{CO})_{\text {gas }}$ formation & $"$ & $-5 \%$ & - & - & -26 \\
$"$ & $\mathrm{E}_{21}$ & $+5 \%$ & -6 & - & - \\
$"$ & $"$ & $-5 \%$ & 6 & - & - \\
$"$ & $\mathrm{E}_{24}$ & $+5 \%$ & - & -4 & - \\
$"$ & $"$ & $-5 \%$ & - & 4 & - \\
$"$ & $\mathrm{E}_{27}$ & $+5 \%$ & - & - & 6 \\
\hline
\end{tabular}




\section{Figures}

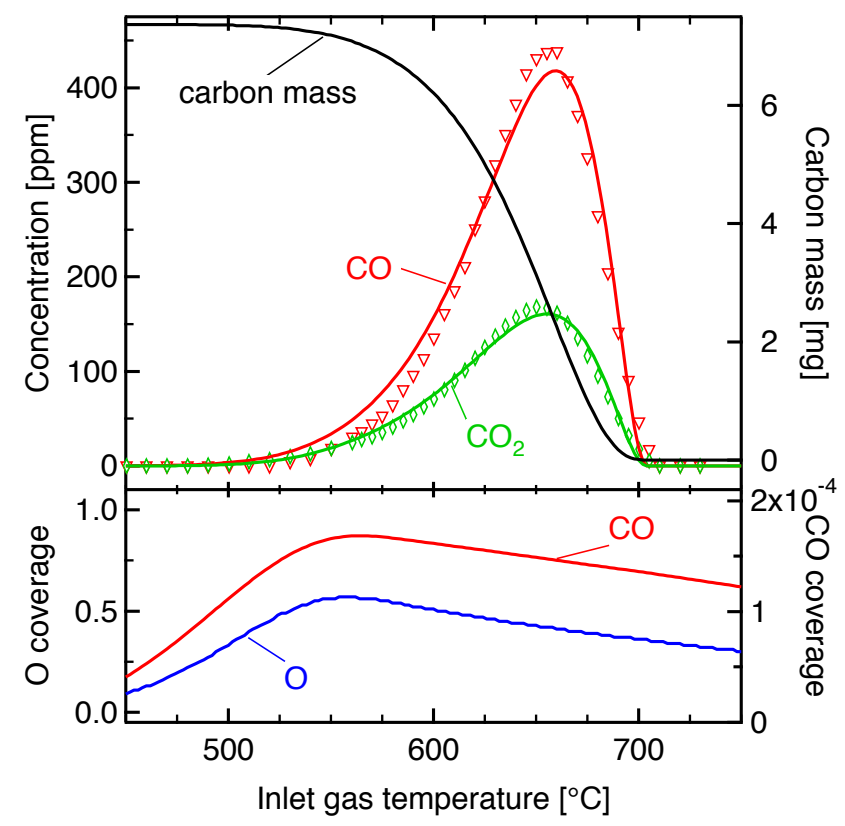

Figure 1: Temperature programmed oxidation of Printex-U using $2 \% \mathrm{O}_{2}$ in $\mathrm{N}_{2}$ at a total flow of $1500 \mathrm{ml} / \mathrm{min}$ and a temperature ramp of $10{ }^{\circ} \mathrm{C} / \mathrm{min}$. The $\nabla$ and $\diamond$ indicate experimental data points. The calculations are based on Eqns. (22) and (23), which rely on the elementary steps (18)-(21), with the Arrhenius parameters for the rate constants given in Table 1. 


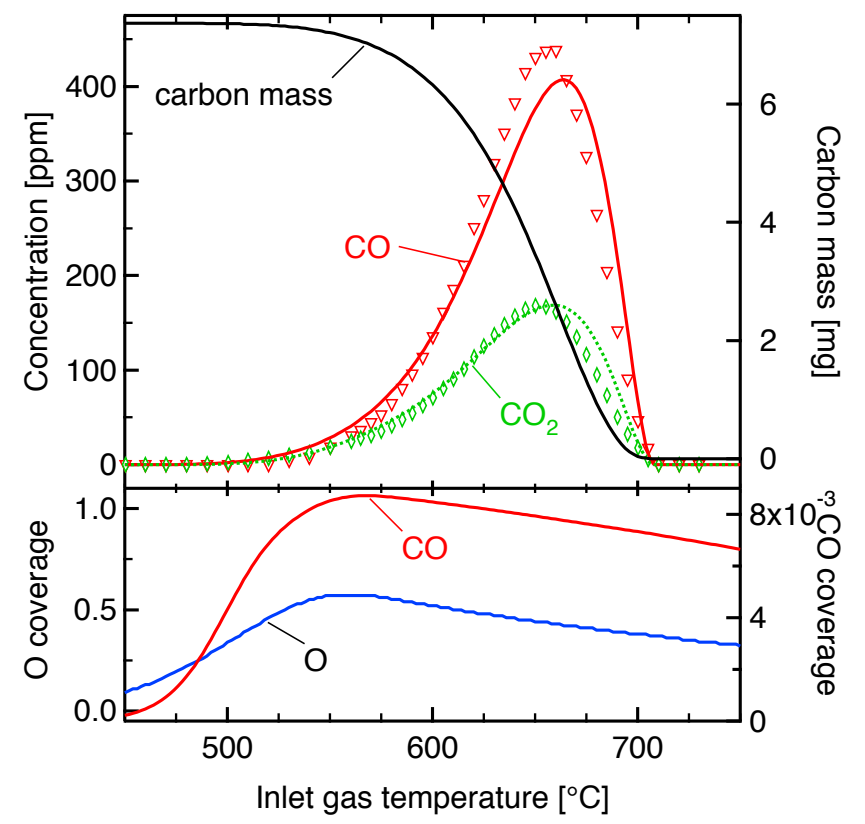

Figure 2: Temperature programmed oxidation of Printex-U using $2 \% \mathrm{O}_{2}$ in $\mathrm{N}_{2}$ at a total flow of $1500 \mathrm{ml} / \mathrm{min}$ and a temperature ramp of $10{ }^{\circ} \mathrm{C} / \mathrm{min}$. The $\nabla$ and $\diamond$ indicate experimental data points. The calculations are based on Eqns. (22) and (25), which rely on the elementary steps (18)-(20) and (24), with the Arrhenius parameters for the rate constants given in Table 1.

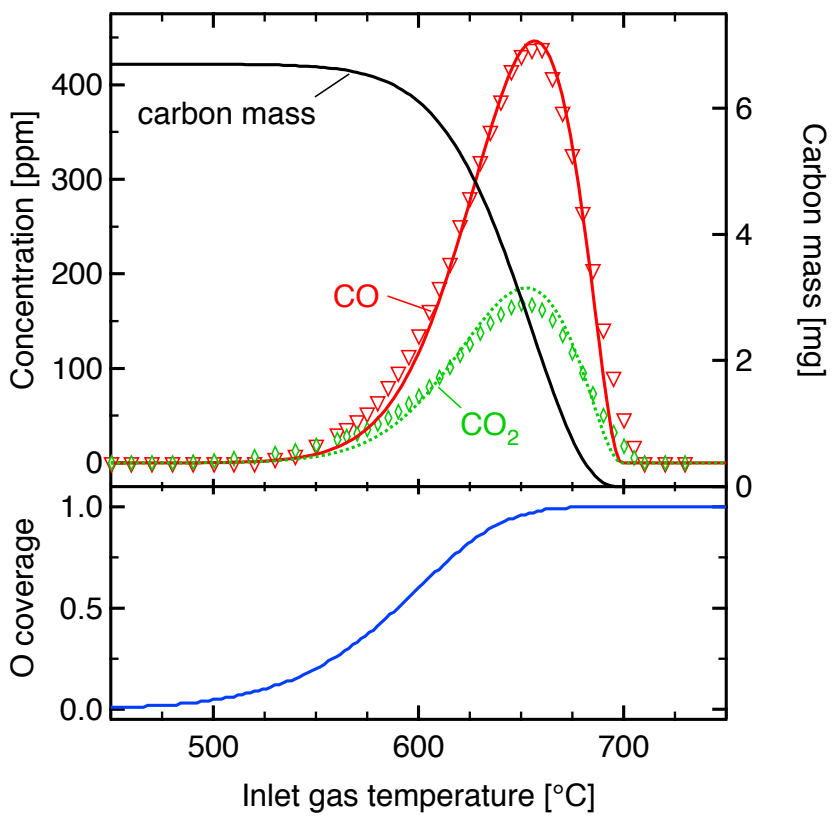

Figure 3: Temperature programmed oxidation of Printex-U using $2 \% \mathrm{O}_{2}$ in $\mathrm{N}_{2}$ at a total flow of $1500 \mathrm{ml} / \mathrm{min}$ and a temperature ramp of $10{ }^{\circ} \mathrm{C} / \mathrm{min}$. The $\nabla$ and $\diamond$ indicate experimental data points. The calculations are based on Eqns. (28)-(30), which rely on the elementary steps (26)(27), with the Arrhenius parameters for the rate constants given in Table 1. 


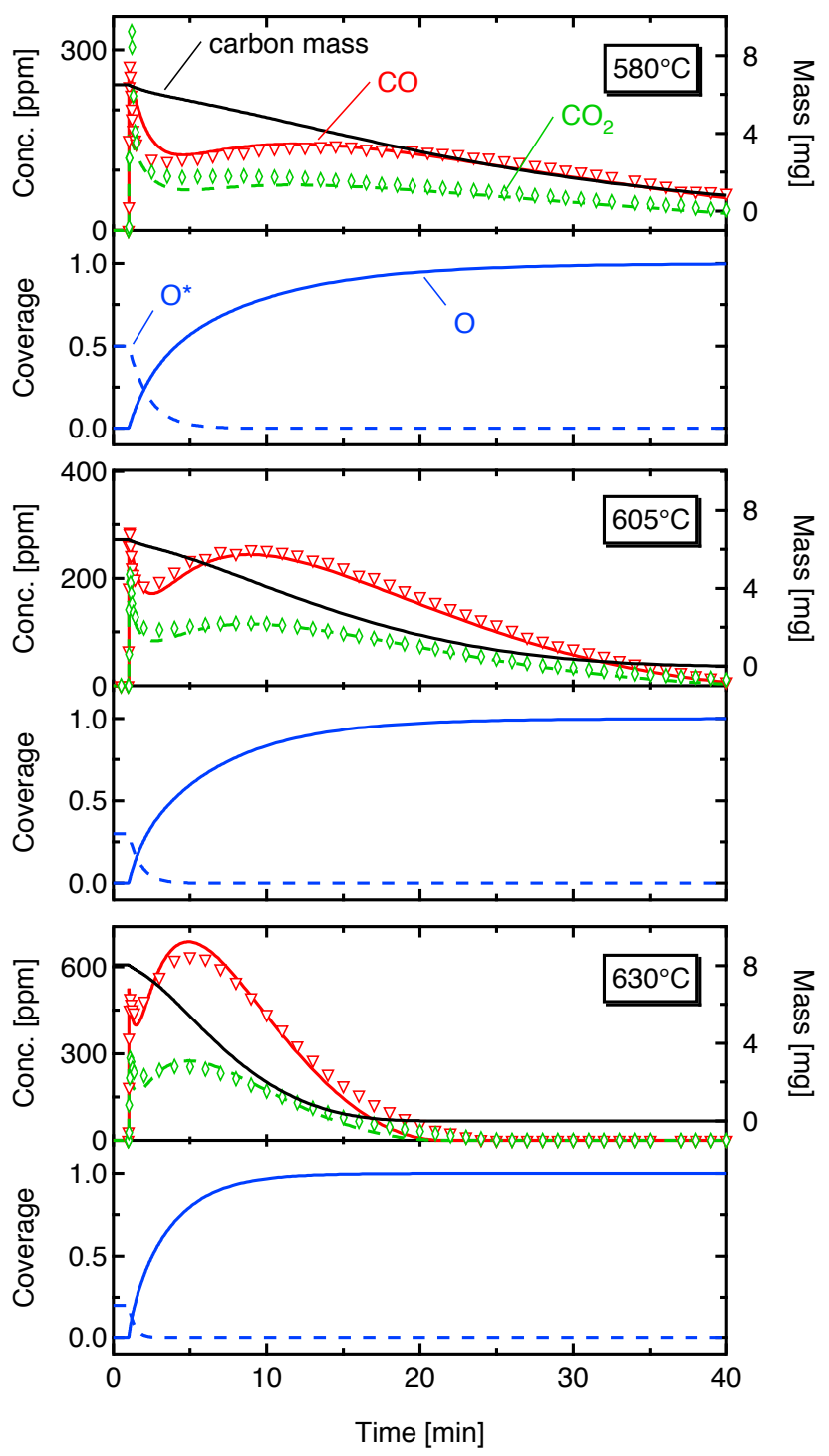

Figure 4: Isothermal oxidation of Printex- $\mathrm{U}$ introducing a stepwise change from 0 to $2 \% \mathrm{O}_{2}$ at $\mathrm{t}=1 \mathrm{~min}$ at a total flow of $1500 \mathrm{ml} / \mathrm{min}$. The $\nabla$ and $\diamond$ indicate experimental data points. The calculations are based on Eqns. (33)-(35), which rely on the elementary steps (18), (26), (27), (31) and (32), with the Arrhenius parameters for the rate constants given in Table 1. 


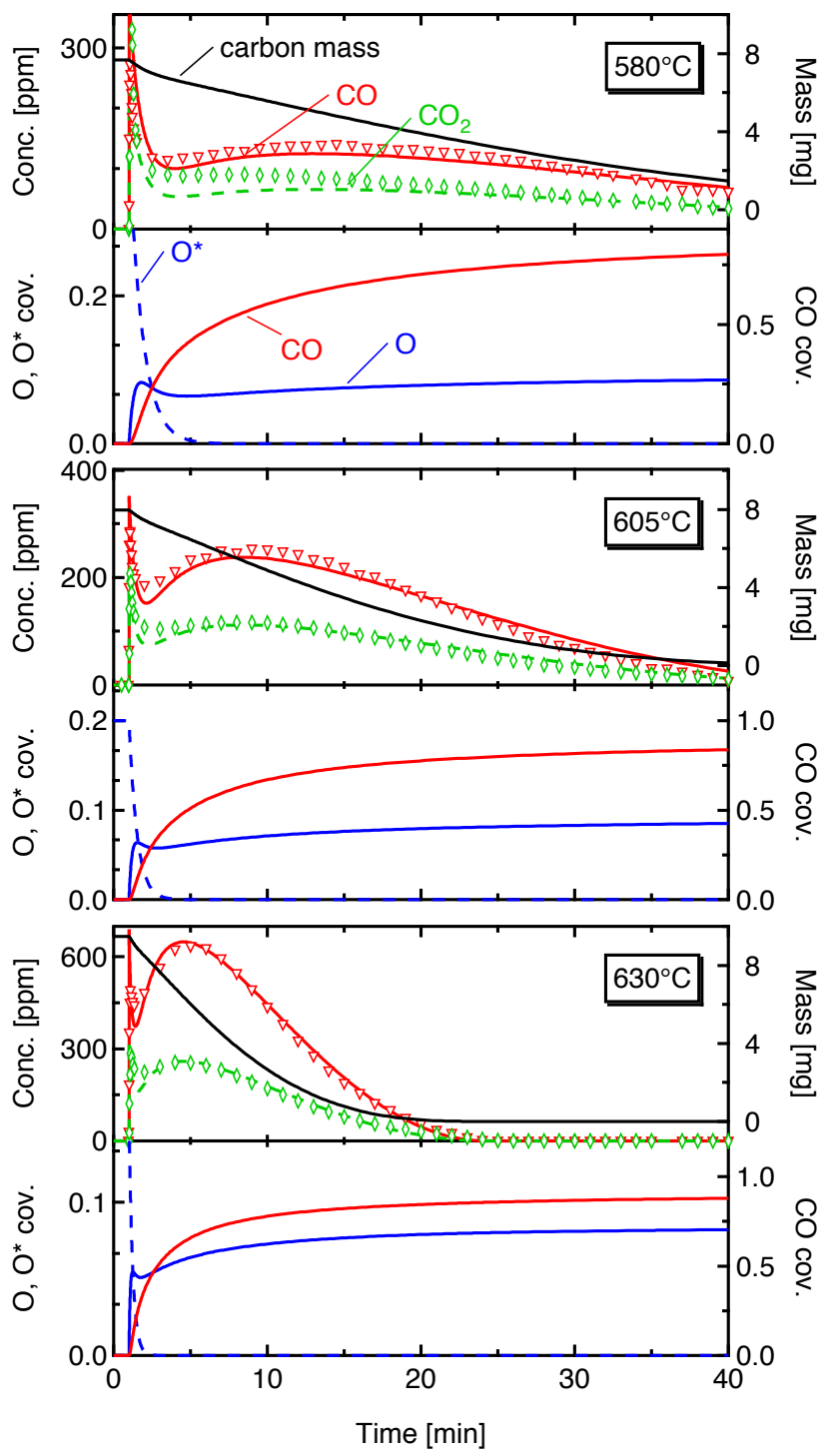

Figure 5: Isothermal oxidation of Printex- $\mathrm{U}$ introducing a stepwise change from 0 to $2 \% \mathrm{O}_{2}$ at $\mathrm{t}=1 \mathrm{~min}$ at a total flow of $1500 \mathrm{ml} / \mathrm{min}$. The $\nabla$ and $\diamond$ indicate experimental data points. The calculations are based on Eqns. (33)-(36), which rely on the elementary steps (18), (19), (31), (32), (37) and (38), with the Arrhenius parameters for the rate constants given in Table 1. 


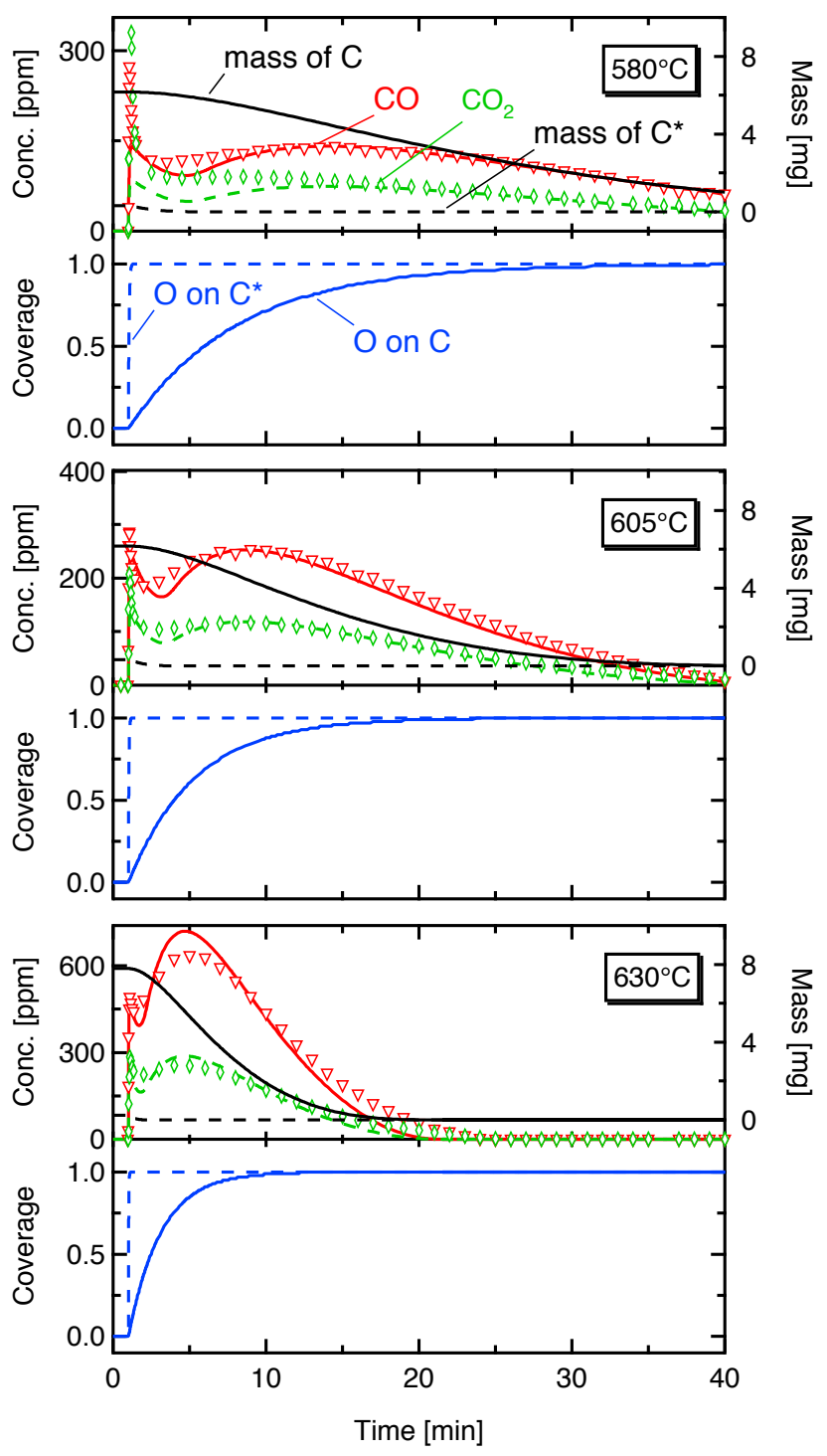

Figure 6: Isothermal oxidation of Printex- $\mathrm{U}$ introducing a stepwise change from 0 to $2 \% \mathrm{O}_{2}$ at $\mathrm{t}=1 \mathrm{~min}$ at a total flow of $1500 \mathrm{ml} / \mathrm{min}$. The $\nabla$ and $\diamond$ indicate experimental data points. The calculations are based on Eqns. (45)-(48), which rely on the elementary steps (18), (26), (27), (42), (43) and (44), with the Arrhenius parameters for the rate constants given in Table 1. 


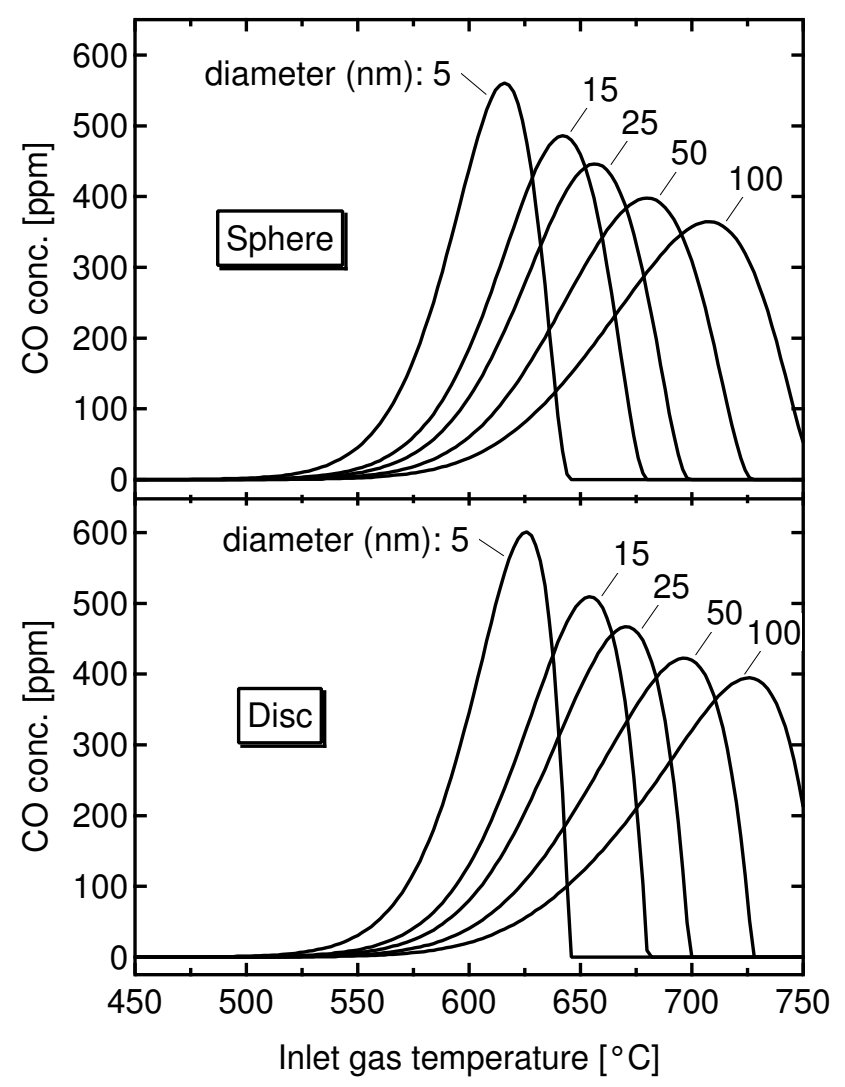

Figure 7: Influence of carbon spherule size and geometry on temperature programmed oxidation of carbon using $2 \% \mathrm{O}_{2}$ in $\mathrm{N}_{2}$ at a total flow of $1500 \mathrm{ml} / \mathrm{min}$ and a temperature ramp of $10 \mathrm{~K} / \mathrm{min}$. The calculations are based on Eqns. (28)-(30), which rely on the elementary steps (26)-(27), with the Arrhenius parameters for the rate constants given in Table 1. 